\section{Commentary: Fontan challenges: Critical early surgical decisions maybe key}

\author{
John M. Karamichalis, MD
}

The Fontan physiology since its inception was never meant to be ideal for the human heart. Nevertheless, it has become the final step in the path of palliating many patients with single-ventricle disease. ${ }^{1}$ Currently, the total cavopulmonary connection or Fontan procedure places the pulmonary circulation like a dam between the systemic venous return and the systemic ventricle, creating, like any dam, upstream congestion and downstream decreased flow. These 2 features are the root cause of all early and late Fontan complications. ${ }^{2}$ Despite the success of the Fontan procedure in palliating single-ventricle congenital heart disease, the circulation achieved by this procedure suffers from inherent physiological flaws: central venous pressure is chronically elevated and cardiac output is chronically diminished. ${ }^{3,4}$ Forcing what nature designed as a 2-ventricle human heart into a single-ventricle physiology, taking away the right ventricular pulsatile augmentation of the pulmonary blood flow, may not be tolerated well by some patients.

The article by Marathe and colleagues ${ }^{5}$ in the current issue of the Journal is a welcome addition to the understanding of long-term outcomes following Fontan takedown in Australia and New Zealand. Over a 43-year study period, the authors found 36 of 1540 , or $2.3 \%$, had a Fontan takedown. Despite the incidence being so low, the mortality of the Fontan takedown was high. The majority of takedowns took place within 6 months, and mortality was lowest when takedown occurred less than 2 days and greatest between 3 weeks and 6 months.

Identifying signs and risk factors for Fontan takedown earlier on appears to be critical; however, these risk factors at present are largely unknown. Even more importantly,

\footnotetext{
From Cardiac Surgery, LeBonheur Children's Hospital and University of Tennessee Health Science Center, Memphis, Tenn.

Disclosures: The author reported no conflicts of interest

The Journal policy requires editors and reviewers to disclose conflicts of interest and to decline handling or reviewing manuscripts for which they may have a conflict of interest. The editors and reviewers of this article have no conflicts of interest.

Received for publication Nov 2, 2020; revisions received Nov 2, 2020; accepted for publication Nov 3, 2020; available ahead of print Nov 7, 2020.

Address for reprints: John M. Karamichalis, MD, LeBonheur Children's Hospital, University of Tennessee Health Science Center, 49 Dunlap St, Level 3, Memphis, TN 38104 (E-mail: jkaramichalis@yahoo.com).

J Thorac Cardiovasc Surg 2021;161:1136-7

0022-5223/\$36.00

Copyright (c) 2020 by The American Association for Thoracic Surgery

https://doi.org/10.1016/j.jtcvs.2020.11.010
}

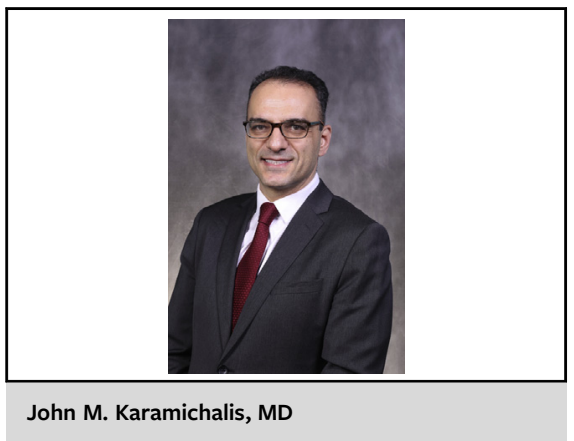

CENTRAL MESSAGE

Recognizing early signs of failure is critical for taking down a Fontan and ensuring best outcomes. Fontan takedown within days of the procedure had the best results. Early surgical decisions are key.

acting upon what may appear early signs of poor physiology following a Fontan and expeditiously taking down a Fontan circulation doomed to fail will avert poor outcomes and death. Having a low threshold for Fontan takedown in patients who show evidence and signs of early failure within hours or days of the procedure is a wise approach as recommended by the authors.

Despite recent advances in the palliation of singleventricle congenital heart disease, which would otherwise be lethal, it seems unlikely that neither cardiac surgeons nor cardiologists will soon come up with the magic solution for the Fontan conundrum provided by millions of years of evolution, that is a subpulmonary pump or the right ventricle. ${ }^{2}$ While a second Fontan procedure after ensuring the appropriate physiology is favorable, and a heart transplantation or a cavopulmonary assist ${ }^{6}$ can instantly solve Fontan problems at the expense of a high-risk intervention, early recognition of the trajectory set by a borderline Fontan physiology may be the wisest first step in averting a long and complicated course of an already-challenging patient population of single-ventricle palliation.

Critical early surgical decisions remain key in averting adverse outcomes in patients who do not fare well in the immediate postoperative period. Fontan takedown within days of the procedure had the lowest mortality. Early recognition for signs of failure within days of the procedure is key. 


\section{References}

1. Fontan F, Baudet E. Surgical repair of tricuspid atresia. Thorax. 1971;26: 240-8.

2. Gewillig M, van de Bruaene A. FUELing the search for medical therapies in late Fontan failure. Circulation. 2020;141:652-4.

3. Gewilling M, Goldberg DJ. Failure of the Fontan circulation. Heart Fail Clin. 2014;10:105-16
4. Goldberg DJ, Zak V, Goldstein BH, Schumacher KR, Rhodes J, Penny DJ, et al Results of the FUEL trial. Circulation. 2020;141:641-51.

5. Marathe SP, Iyengar AJ, Betts KS, du Plessis K, Salve GG, Justo RN, et al. Longterm outcomes following Fontan takedown in Australia and New Zealand. $J$ Thorac Cardiovasc Surg. 2021:161:1126-35.

6. Rodefeld MD, Masden A, Figliola R, Jonas T, Neary M, Giridharan GA. Cardiopulmonary assist: long-term reversal of the Fontan paradox. J Thorac Cardiovasc Surg. 2019;158:1627-36.
See Article page 1126.

\section{Commentary: Fontan takedown: The journey off the beaten path}

\section{Matteo Trezzi, MD}

Marathe and colleagues ${ }^{1}$ queried the Australia and New Zealand Fontan Registry to evaluate early and late outcomes of patients who had undergone a Fontan takedown procedure.

Over a 43-year study period (1975-2018), 36 of 1540 $(2.3 \%)$ patients had a Fontan takedown at a median age of 5.1 years (interquartile range, 3.7-7.0 years) with most takedowns occurring within 6 months after the index operation. A total of 16 patients died and data showed mortality was lowest when takedown occurred within 2 days after acute Fontan failure, and highest when done 3 to 24 weeks postcomplication. Eleven patients with an intermediate palliative circulation ( 8 with bidirectional superior cavopulmonary anastomosis) were alive at a median follow-up of 9.4 years. Five patients underwent a second Fontan operation after a median of 4.4 years and only 1 had a late failure. No remediable cause was identified in any patient before the second Fontan operation. Three other patients underwent biventricular or 1.5 -ventricle repair.

Another publication reported that preoperative characteristics were not associated with an increased risk of failure and showed no correlation to the type of Fontan

\footnotetext{
From the Department of Pediatric Cardiology and Cardiac Surgery, Bambino Gesù Children's Hospital IRCCS, Rome, Italy.

Disclosures: The author reported no conflicts of interest.

The Journal policy requires editors and reviewers to disclose conflicts of interest and to decline handling or reviewing manuscripts for which they may have a conflict of interest. The editors and reviewers of this article have no conflicts of interest.

Received for publication Sept 30, 2020; revisions received Sept 30, 2020; accepted for publication Sept 30, 2020; available ahead of print Oct 10, 2020.

Address for reprints: Matteo Trezzi, MD, Department of Pediatric Cardiology and Cardiac Surgery, Bambino Gesù Children's Hospital IRCCS, Piazza S Onofrio 4, 00165 Rome, Italy (E-mail: trezzim@hotmail.com).

J Thorac Cardiovasc Surg 2021;161:1137-8

$0022-5223 / \$ 36.00$

Copyright (c) 2020 by The American Association for Thoracic Surgery

https://doi.org/10.1016/j.jtcvs.2020.09.128
}

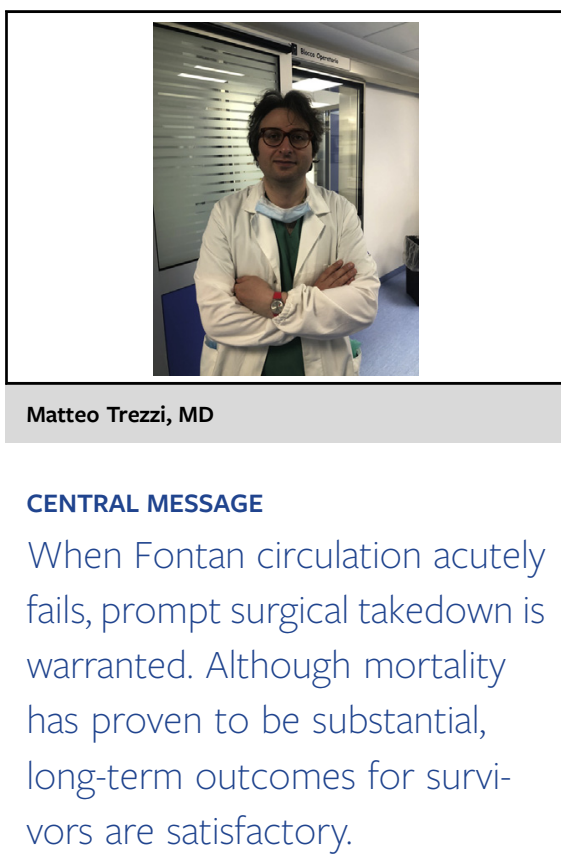

(atriopulmonary vs lateral tunnel vs extracardiac conduit). ${ }^{2}$ Fifteen $(41.6 \%)$ patients had a single-stage Fontan, although this was found not to be statistically significant. In addition, patients who underwent initial hybrid palliation were not included in the study, which represents a topic for further investigation.

Due to the high mortality risk associated with Fontan failure, $13(27 \%)$ patients had 14 rescue procedures performed before takedown, including Fontan revision, enlargement of fenestration, coiling of aortopulmonary collaterals, pacemaker insertion, left pulmonary artery stenting, and removal of bronchial cast.

Early failure of Fontan circulation is rare $(\sim 2 \%)$, but remains associated with a high mortality rate due to the fact that these patients are often poor surgical candidates for a rescue procedure. The pathophysiology of acute failing Fontan circulation is characterized by a 